\title{
USO DE TECNOLOGIA EM SALA DE AULA: YOUTUBE RECURSO PARA O ENSINO DE LÍNGUA INGLESA
}

\author{
THE USE OF TECHNOLOGY IN THE CLASSROOM: YOUTUBE \\ AS A RESOURCE FOR ENGLISH LANGUAGE TEACHING
}

\section{Patrícia Vasconcelos Almeida ${ }^{1}$ Joyce dos Santos Honório ${ }^{2}$}

\begin{abstract}
RESUMO: O presente artigo tem como tema o uso da tecnologia, mais especificamente o computador em sala de aula trazendo o site Youtube como um recurso didático para o ensino da língua inglesa. Buscando apresentar a importância de um artefato tecnológico em sala de aula para o ensino-aprendizagem da língua inglesa, o recorte deste artigo visa mostrar os pontos positivos e negativos de utilizar o computador conectado a internet em sala de aula tendo como pano de fundo os recursos do Youtube. A pesquisa é de cunho qualitativo e comparativo confronta o conteúdo de alguns canais: Inglês com Séries, Jennifer ESL e Inglês Winner a fim de perceber se a tecnologia digital e o vídeo em sala de aula podem vir a ser ferramentas úteis e que podem auxiliar o professor no processo de ensino de uma língua estrangeira. Tendo como fundamentação teórica os trabalhos na área do ensino de línguas mediadas pelas tecnologias digitais foi possível perceber que os recursos do site podem viabilizar uma proposta de ensino diversificada e desafiadora e uma aprendizagem engajada e autônoma.
\end{abstract}

Palavras-chave: Ensino-aprendizagem; Língua Estrangeira; Tecnologia Digital.

\begin{abstract}
This article has as its theme the use of technology, more specifically the computer in the classroom using the YouTube site as a didactic resource for teaching English. In order to present the importance of a technological artifact in the classroom for teaching and learning English language, the main goal of this article aims to show the positive and negative points of using the computer connected to the internet in the classroom using the resources from YouTube. The research is qualitative and comparative. It confronts the content of some channels: English with Series, Jennifer ESL and English Winner in order to realize if digital technology and video in the classroom can to be useful tools to assist the teacher in the process of teaching a foreign language. Having as a theoretical foundation the works which deals with computer assisted language learning it was possible to perceive that the resources of the site can make feasible a diversified and challenging teaching proposal and engaging and autonomous learning.
\end{abstract}

Keywords: Teaching-learning; Foreign Language; Digital Technology.

\section{Introdução}

Qual a importância de se aprender uma língua estrangeira? Como o computador conectado a internet e todos os seus recursos digitais podem ser utilizados como ferramenta mediadora no ensino-aprendizagem de língua estrangeira? Qual o envolvimento dos sujeitos com a oportunidade/estratégia de aprendizado por meio da tecnologia digital?

Essas perguntas vêm norteando os trabalhos acadêmicos referentes ao processo de ensinoaprendizagem de línguas mediada pelas tecnologias digitais (Stockwell, 2012) e por essa razão o objetivo deste artigo é ponderar sobre os desafios de inserir as tecnologias digitais no ensino-

\footnotetext{
${ }^{1}$ Doutora em Linguística Aplicada; professora na Universidade Federal de Lavras. E-mail: almeidaufla@gmail.com

${ }^{2}$ Graduanda em Letras na Universidade Federal de Lavras. E-mail: joyelse13@hotmail.com
} 
aprendizado de línguas, mais especificamente o inglês, e como elas podem vir a beneficiar no campo social e individual dos sujeitos envolvidos neste processo.

Com o processo de globalização mundial, tanto nas áreas políticas, econômicas, sociais, tecnológicas quanto educacionais e profissionais, a língua inglesa passou a ter destaque e ser considerada como a língua universal. Por essa razão, as pessoas, em grupo ou individualmente, passaram a ter a necessidade de se envolver com a aprendizagem da língua e suas várias manifestações de linguagem. Vale destacar que segundo Grigoletto (s.d.) a importância de se ter o domínio das habilidades de linguísticas da língua inglesa está ligada principalmente, ao fato de que o inglês é o idioma mais falado no mundo e consequentemente o mais ensinado. Além disso, por ser a língua que prevalece para as relações de comunicação em vários setores da sociedade inovações em benefício da sua aprendizagem surgem constantemente.

Embora essa posição de destaque da língua inglesa seja reconhecida mundialmente, no Brasil ainda há uma deficiência, tanto no processo de ensino-aprendizagem da língua quanto no seu uso. De acordo com uma pesquisa feita em 2013 pelo BRITISH COUNCIL (Organização Internacional do Reino Unido para Relações Culturais e Oportunidades Educacionais) apenas 5\% dos brasileiros falam a língua e menos de 1\% apresenta algum grau de fluência. Ainda referente à realidade sobre o ensino da língua no país, podemos mencionar as informações do Instituto de Pesquisas Plano CDE de 2015, que pontuam o fato de a língua inglesa não ser vista como primordial para os brasileiros. A justificativa é a dificuldade de traçar um plano de estudo com uma base curricular voltado exclusivamente para o ensino da língua, e por esse motivo, a língua inglesa continua a ser trabalhada de forma complementar nas escolas públicas, local onde normalmente o idioma ocupa uma carga horária mínima e ainda é negligenciado pelos aprendizes por não reconhecer nele uma necessidade social eminente. Essa falta de maturidade dos envolvidos no processo de ensino-aprendizagem acaba por afetar a inclusão do Brasil num ambiente globalizado, devido a não fluência linguística em inglês de seus habitantes.

Outra dificuldade/crença "enraizada" no contexto de ensino-aprendizagem da língua inglesa nas escolas está relacionada à habilidade de falar a língua. No senso comum, e também apresentado em vários estudos acadêmicos considerados etnográficos, os alunos se entendem não capazes de se manifestar utilizando essa habilidade e veem obstáculos em buscar desenvolvê-la. Nesse mesmo contexto, os professores também encontram dificuldade em melhorar sua própria competência oral (linguístico-discursiva), e muitas vezes eles atribuem este fato a uma má formação docente e uma inviabilidade de buscarem uma formação continuada.

Todo esse processo circular, que envolve o ensino-aprendizagem de língua estrangeira (inglês) esbarra também em questões subjetivas que envolvem o aprendizado. O professor enquanto aprendiz da língua quando não desenvolve a fluência necessária, ao se encontrar dentro da sala de aula, evita a sua verbalização, focando apenas na habilidade de leitura. Atitude esta normalmente justificada pelos objetivos frente aos meios de ingresso nas universidades, ou seja, as necessidades eminentes dos alunos. Porém, já no final do século passado, o contexto social em que os alunos estão inseridos começa a se modificar devido a sua recorrente exposição às inovações tecnológicas. Como a língua inglesa é mundialmente a língua utilizada para comunicação, a maioria das informações recebidas por meio das inovações tecnológicas digitais chega para os alunos na língua inglesa. Assim, eles passam a demandar das instituições escolares uma nova postura frente ao seu ensino.

A inserção das inovações tecnológicas digitais no âmbito escolar trouxe, em seu início, desconfiança e rejeição por parte dos professores, os quais se sentiram ameaçados frente à novidade. Mas atualmente esse contexto se modificou e Paiva (2008) assegura que após o começo duvidoso, o computador conectado à internet no contexto educacional foi se transformando em um instrumento de uso geral e viável para o ensino de línguas estrangeiras, pois possibilitava o acesso à aprendizagem de língua inglesa para além dos muros das escolas.

Pensar no ensino da língua inglesa por meio da tecnologia digital, mais especificamente, o computador conectado à internet dentro do contexto escolar ou não, e fazer uso dos inúmeros 
recursos que ele pode oferecer continua sendo um tópico de pesquisa relevante. As perspectivas e desafios que envolvem, por exemplo, utilizar os recursos do Youtube (site que disponibiliza canais de vídeos que abrangem diversos conteúdos referentes à língua inglesa) em benefício do ensino de língua inglesa, devem ser socializadas tanto no meio acadêmico de formação de futuros professores, bem como para os professores em serviço, pois uma de suas características é promover uma interação entre as pessoas e os conteúdos de aprendizagem, uma condição importante na sociedade de hoje.

Segundo Leffa (2006), é relevante trazer para as discussões atuais na formação docente sobre a necessidade de se usar o computador conectado à internet para o ensino-aprendizagem de línguas, já que este é uma ferramenta tão importante quanto o livro didático. Mais do que a ferramenta em si, os recursos tecnológicos oferecidos pelo computador conectado à internet diminui a distância entre o real (falante nativo da língua) e o aprendiz da língua. $O$ artefato fornece meios para que o professor estreite sua relação com seu aluno e forneça a ele possibilidades de exposição à língua inglesa que antes não eram possíveis. Em outras palavras, o professor habilitado para o ensino mediado pelo computador pode vir a facilitar o aprendizado e até a relação entre ele e o aluno.

Especificamente sobre o desafio das relações entre professores e alunos, é comum em muitas escolas se vê uma distância entre eles. Essa falta de proximidade pode vir a ser um fator contribuinte para uma formação deficitária do aluno, principalmente no que tange à língua inglesa, pois ele não se vê seguro em relação ao que está aprendendo e não se sente à vontade para se fazer ouvir. Duarte e Tito (2010) apontam que deve haver um aperfeiçoamento da prática didática por parte do professor, um envolvimento interpessoal onde ele se mostra de outra forma para o aluno, tirando a "máscara" de ser um alguém superior em sala de aula e sendo ele mesmo.

Neste viés, defende-se aqui que a utilização das tecnologias digitais, que estão diretamente no cotidiano dos alunos, para as práticas docentes de língua inglesa, pode vir a criar uma maior afinidade com o aprendiz, dando espaço para este se aproximar tanto da língua quanto do professor e dessa maneira viabilizar uma aprendizagem significativa. A relação entre aluno e professor é um espaço para que esses sujeitos se entendam, aprendam e ensinem e o computador pode ser um mediador importante nessa relação interpessoal.

Ao fazer uso deste artefato conectado à internet no contexto da sala de aula, o professor estará instigando a curiosidade do aluno para a complexidade do artefato e seus conteúdos para fins educacionais, gerando um interesse que pode vir a resultar em uma postura diferenciada de aprendizagem. Poderá existir um interesse em saber mais do que é oferecido em sala de aula e essa busca pode acabar por aproximar o aluno do professor, e ambos se tornarem motivados: o professor em conseguir estabelecer uma maneira para estimular a construção do conhecimento para o aluno e o aluno em querer aprender aquilo que lhes está sendo ensinado.

No caso da língua inglesa, mote deste artigo, o computador conectado à internet pode vir a ser uma opção de ensino-aprendizagem. Utilizado para auxiliar a concentração do aluno no conteúdo, ele também pode vir a oferecer maneiras para possibilitar uma construção do conhecimento colaborativo. Por meio dele é possível o professor disponibilizar em sala de aula materiais autênticos reproduzindo amostras de falas de falantes nativos, todo tipo de vídeos incluindo os musicais que são atrativos para os alunos, filmes com legendas em língua inglesa, animações, exercícios auditivos e visuais, aproveitando assim da multimodalidade e semioses que o artefato oferece. Com esses recursos pode haver uma maior facilidade e um maior interesse em se aprender a língua, criando também uma proximidade com outras culturas e povos, o que pode se dá por meio de atividades sociais.

As atividades sociais por meio do computador são percussoras do ensino, passando também a ser fundamental para o desenvolvimento pessoal do aluno. A esse respeito Liberali (2012) argumenta que as atividades sociais podem ser realizadas também por meio de jogos e brincadeiras e essas duas opções são consideradas pela autora muito pertinentes para o ensino de aspectos culturais da língua. Além disso, as atividades que envolvem o lúdico geralmente tratam de ques-

https://periodicos.unifap.br/index.php/letras

Macapá, v. 9, n. 3, $2^{\circ}$ sem., 2019 
tões por meio da experimentação, o que pode vir a desenvolver no aprendiz seu senso crítico, além de oferecer oportunidade para vivenciarem situações diferentes da sua realidade cotidiana. Segundo Liberali (2012), essas possibilidades podem suscitar questionamentos e reflexões sobre os valores e os conceitos sociais que é muito significativo para o ensino da língua inglesa.

Esses valores e conceitos sociais também são importantes na opinião de Pavan e Oger (2009), que (re)afirmam a importância do ensino de línguas em um mundo globalizado e repleto de inovações tecnológicas. Segundo os autores, essas inovações estabelecem novas conexões virtuais e por essa razão expõe as pessoas a novas línguas e novos hábitos sociais, e, por conseguinte o ensino de línguas passa a ser oferecido de várias outras formas para além do contexto tradicional de sala de aula. Neste cenário de atuação o professor precisa desenvolver habilidades para guiar seus alunos por meio das transformações e informações que ocorrem a todo o momento no mundo virtual, e os alunos precisam buscar sentido para o que está sendo ensinado. Por esta razão, o presente artigo tem como destaque abordar questões sobre o uso do Youtube como mediador de ensino da língua inglesa, mostrando os pontos positivos e negativos de se usar essa ferramenta como um instrumento de ensino nos contextos da sala de aula ou de forma autônoma.

\section{Fundamentação teórica}

As tecnologias digitais estão presentes no contexto atual dos estudantes, o que em nossa percepção torna viável a utilização desses recursos, por parte do professor, em sala de aula. Segundo Marcuschi (2005, p.11), "se até ontem parecia um luxo dedicar-se ao ensino dos usos da Internet, hoje é uma necessidade, pois esta tecnologia tornou-se irreversível e invasora de todos os ambientes.", e é nessa perspectiva que surgem pesquisas e discussões sobre as maneiras de se ensinar uma língua estrangeira (LE) por intermédio das tecnologias digitais (TD). Desta forma, este texto tem como intuito corroborar com os estudos da área discutindo os efeitos da inserção das TDs na educação, mais especificamente o Youtube, apresentado aqui como um artefato pedagógico de ensino-aprendizagem de línguas.

O Youtube é um site conhecido por sua diversidade em recursos multimidiáticos. Segundo Kampff e Dias (2003, p. 10) essa multimídia na educação é uma "estratégia poderosa na utilização de múltiplos recursos que contemplam diferentes percepções do ser humano". Especificamente para o contexto do trabalho que resultou nesse artigo destacamos que um dos recursos da multimídia é o vídeo, e suas diversas possibilidades de uso para a educação acabou por transformá-lo em uma estratégia em benefício do processo de ensino-aprendizagem. Um dos fatores foi o seu uso ser considerado como uma forma de entretenimento, o que pode vir a possibilitar um grau de interesse e produtividade por parte dos alunos, segundo Moran (1995, p.1),

O vídeo está umbilicalmente ligado à televisão e a um contexto de lazer, e entretenimento, que passa imperceptivelmente para a sala de aula. Vídeo, na cabeça dos alunos, significa descanso e não "aula", o que modifica a postura, as expectativas em relação ao seu uso. (Moran, 1995, p.1)

Apesar do postulado por Moran, ainda há alguma dificuldade em "aceitar" o uso dessa tecnologia em sala de aula. De acordo com Vieira (2010), uma delas seria a resistência dos professores ao fazer uso do computador, muitas vezes por não ter o domínio da ferramenta. Ainda assim, o vídeo é uma ferramenta importante e poderosa no meio educacional, além facilitar a fixação da matéria pelo aluno ele também desperta seu interesse e o permite criar e explorar novos conteúdos, Moran (1995, p.1) defende essa ideia ao dizer, 
O vídeo ajuda a um bom professor, atrai os alunos, mas não modifica substancialmente a relação pedagógica. Aproxima a sala de aula do cotidiano, das linguagens de aprendizagem e comunicação da sociedade urbana, mas também introduz novas questões no processo educacional. (Moran, 1995, p.1)

Considerando o ensino-aprendizado de línguas, podemos dizer que, o que foi postulado pelo autor corrobora com a ideia que temos que o site Youtube e seus recursos audiovisuais. O Youtube é um site de compartilhamento de vídeos, acessível para todos que queiram assistir e compartilhá-los e é considerado o site de vídeo mais popular, segundo Werneck e Cruz (2009, p.8) este fato se dá devido à

Possibilidade de hospedar quaisquer vídeos, com ele pessoas de todo mundo podem enviar seus vídeos digitais, gravados a partir de filmadoras caseiras, webcams e até celulares para compartilhar com os outros usuários do site. Seu formato permite que os usuários coloquem seus vídeos em blogs, ou sites pessoais através de mecanismos desenvolvidos pelo site. (Werneck e Cruz, 2009, p.8)

Todos os dias são disponibilizados milhares de vídeos para serem assistidos. Tamanha acessibilidade e disponibilidade de interação entre os usuários desperta interesse também por parte dos educadores que passam a reconhecer o site como um recurso didático viável. A facilidade de acesso e também de tornar o Youtube um "repositório" de informações pedagógicas, possibilita o reforço das matérias aprendidas pelo aluno em sala de aula, ou até mesmo acrescentar conhecimentos que até então não foram adquiridos na escola.

No caso do ensino-aprendizado do inglês, o Youtube é uma ferramenta útil por disponibilizar diversos vídeos em canais criados por professores, ou alguém com grande conhecimento da língua, e até mesmo por nativos de determinada região em que se faz uso do idioma. Extrapolando a ideia de que vídeo é só imagem e som Moran (1995, p.2) afirma:

O vídeo é também escrita. Os textos, legendas, citações aparecem cada vez mais na tela, principalmente nas traduções (legendas de filmes) e nas entrevistas com estrangeiros. A escrita na tela hoje é fácil através do gerador de caracteres, que permite colocar na tela textos coloridos, de vários tamanhos e com rapidez, fixando ainda mais a significação atribuída à narrativa falada. $\mathrm{O}$ vídeo é sensorial, visual, linguagem falada, linguagem musical e escrita. Linguagens que interagem superpostas, interligadas, somadas, não separadas. Daí a sua força. (Moran, 1995, p.2)

Tendo essas opções em benefício do ensino de língua inglesa (LI), podemos afirmar que utilizar métodos audiovisuais como o Youtube pode vir a estimular o professor a se apoderar desse meio mediático a fim de poder interagir com o aluno e levar o conhecimento a ele de uma forma atrativa. Pegamos emprestadas as palavras de Fisher (2002, p. 153) quando o autor busca uma conclusão para a questão do uso das tecnologias digitais em sala de aula: "Em suma: torna-se impossível fechar os olhos e negar-se a ver que os espaços da mídia constituem-se também como lugares de formação - ao lado da escola, da família, das instituições religiosas".

Isto posto, retomamos nossa posição em relação ao uso do vídeo em sala de aula, e reiteramos que ele pode vir a ser uma ferramenta poderosa na mão do professor e cabe a ele fazer uso dessa ferramenta de modo a proporcionar uma maior rede de informação, fixação e interação com seus alunos. É importante que o professor entenda e explore os meios mediáticos de ensino, como o Youtube, reconhecendo-o como um elemento que trará resultado na aprendizagem dos alunos. É preciso que o professor esteja disposto a ensinar, mas também a aprender, fazendo desse ensino-aprendizagem não uma obrigação, mas uma arte a ser desenvolvida e aprendida. 


\section{Metodologia}

A pesquisa aqui apresentada foi embasada teoricamente em alguns autores como: Paiva (2008), Leffa (2006), Liberali (2012), Marcuschi (2005), Moran (1995), Fisher (2002) e por meio de seus trabalhos se desencadeou a ideia de fazer uma análise dos canais de Youtube: Inglês com Séries, Jennifer ESL e Inglês Winner. Nos moldes da pesquisa qualitativa e descritiva os sites foram estudados e comparados buscando mostrar e exemplificar o conteúdo que cada um deles oferece para o ensino de LI. As comparações foram feita de modo que mostre ao leitor deste artigo o que ele pode encontrar em cada um dos canais e em que aspectos eles podem ser úteis para o ensino de LI.

Como mencionado, a pesquisa tem cunho qualitativo como método de investigação cientifica com enfoque no caráter subjetivo do objeto pesquisado, mostrando suas particularidades. Segundo Godoy (1995), a pesquisa qualitativa tem como contexto o seu ambiente natural, e normalmente são os pesquisadores estão preocupados em compreender seus dados levando em consideração a experiência vivenciada no contexto de investigação. Já a pesquisa comparativa é um método de investigação que expõe as diferenças e as semelhanças do que está sendo pesquisado. Como o objetivo da pesquisa em questão é conhecer o Youtube como um site capaz de oferecer oportunidades de ensino-aprendizagem de línguas, acreditamos que os dados deveriam ser apresentados sob esses dois vieses.

Desta forma, os canais foram selecionados levando em consideração que seu conteúdo poderia ser utilizado para atender todos os tipos de aprendiz: do nível básico ao avançado. Além disso, levou-se em consideração também como critério de seleção dos canais, o fato de terem opções diversificadas de tipos de conteúdos, foco de instrução e recursos multimidiáticos: vocabulários, gramática, tradução, pronúncia, séries, músicas dentre outros. Após seleção, foram comparados e analisados levando em consideração o que foi postulado na literatura supramencionada.

\section{Análise de dados}

Partimos agora para apresentação dos canais analisados. Temos: as características, os recursos audiovisuais, suas vantagens e desvantagens. Serão apresentados três quadros fazendo a comparação dos parâmetros que decidimos destacar: níveis de dificuldade, recursos audiovisuais e conteúdo.

\section{O primeiro - Inglês com Séries}

Características: analisa séries com foco na pronúncia, na compreensão auditiva das palavras e na tradução do inglês. É selecionada uma cena de alguma série, e por meio dela é feito um estudo sobre as palavras e suas pronúncias. O uso dessa estratégia torna o canal divertido e interessante o que pode facilitar a compreensão e fixação dos vocábulos. Os vídeos duram em torno de 8 a 17 minutos.

Recursos audiovisuais: o canal contém cenas e áudios de séries, com legendas em inglês e português. A análise é feita por um apresentador fisicamente ausente onde ele explica o contexto das cenas e as palavras ali utilizadas. Seguem os prints como exemplo do material que está disponível nos vídeos do canal analisado. 
Fig 1- canal Inglês com série - Disponível em: https://www.youtube.com/watch?v=XJJRbB4P01Q>

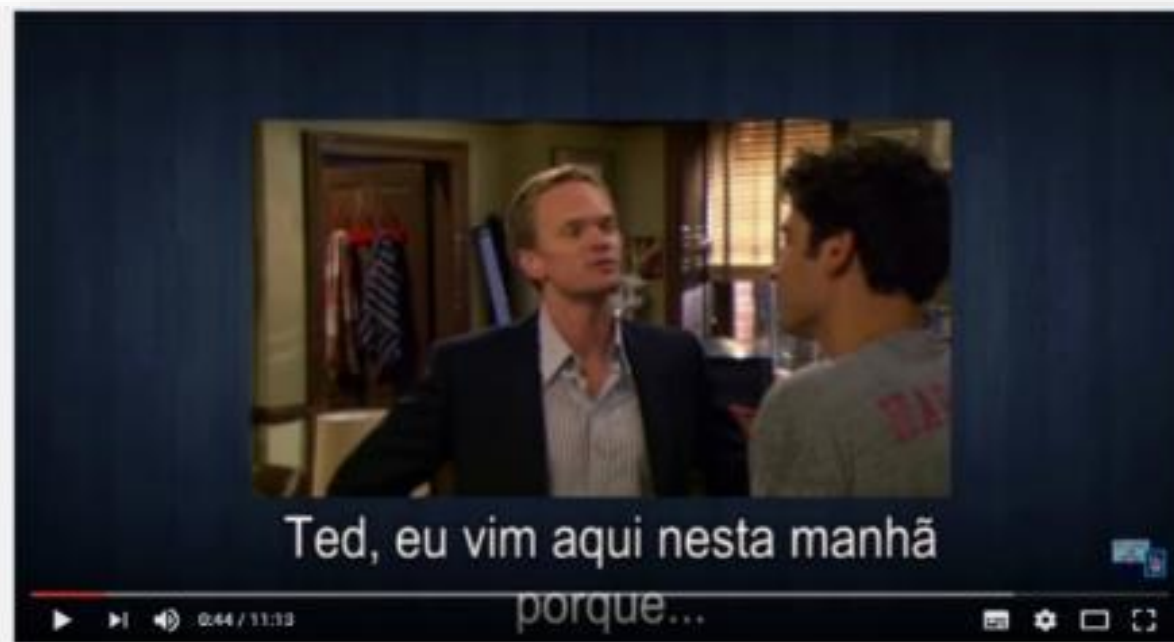

Aprenda inglês com séries - HOW I MET YOUR MOTHER \#2 [S03E01]

Fig 2 - canal Inglês com Série - Disponível em: $<$ https://www.youtube.com/watch?v=XJJRbB4P0lQ>

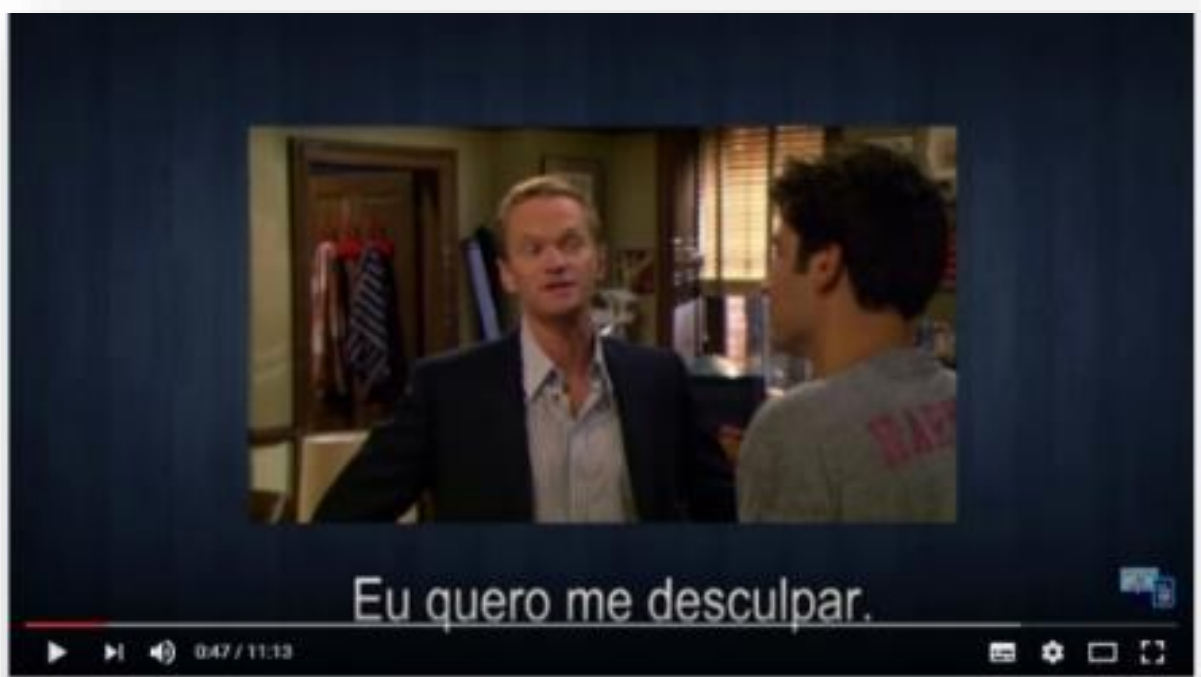

Aprenda inglês com séries - HOW I MET YOUR MOTHER \#2 [S03E01]

Existe também uma preocupação com as traduções daquilo que está sendo dito, assim o interlocutor pode acompanhar o desenrolar da história e compreender a pronúncia das palavras e os seus significados (visível nos vídeos). O canal também trabalha com a maneira de pronunciar as palavras. Elas são apresentadas nas cenas considerando a forma em que elas são pronunciadas levando em conta os sons das letras com suas transcrições fonéticas mostrando ao interlocutor sua forma correta de pronunciar. O canal possibilita o trabalho com a gramática, visto que apresenta uma legenda na LI. Pode-se deduzir que a intenção do canal seja, além de fazer com que o interlocutor compreenda o que está sendo dito, ele também seja capaz de fazer o uso de sua escrita. 
Fig. 3 - canal Inglês com Série - Disponível em: $<$ https://www.youtube.com/watch?v=XJJRbB4P01Q $>$

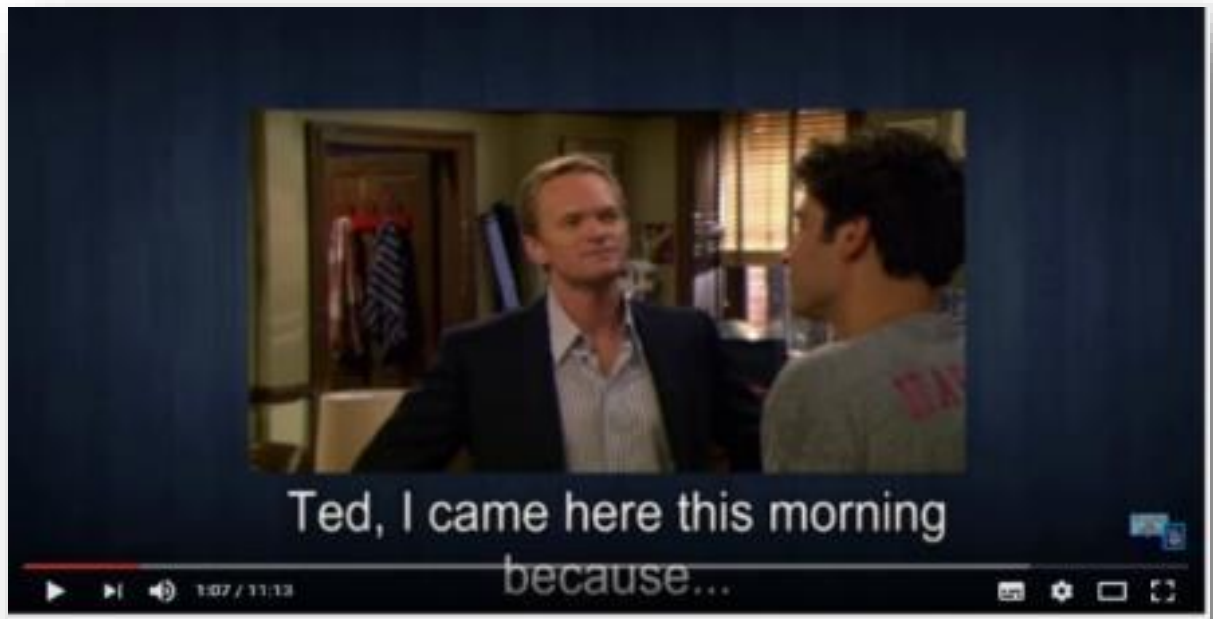

Aprenda inglês com séries - HOW I MET YOUR MOTHER \#2 [S03E01]

Fig. 4 - canal Inglês com Série - Disponível em: <https://www.youtube.com/watch?v=XJJRbB4P01Q>

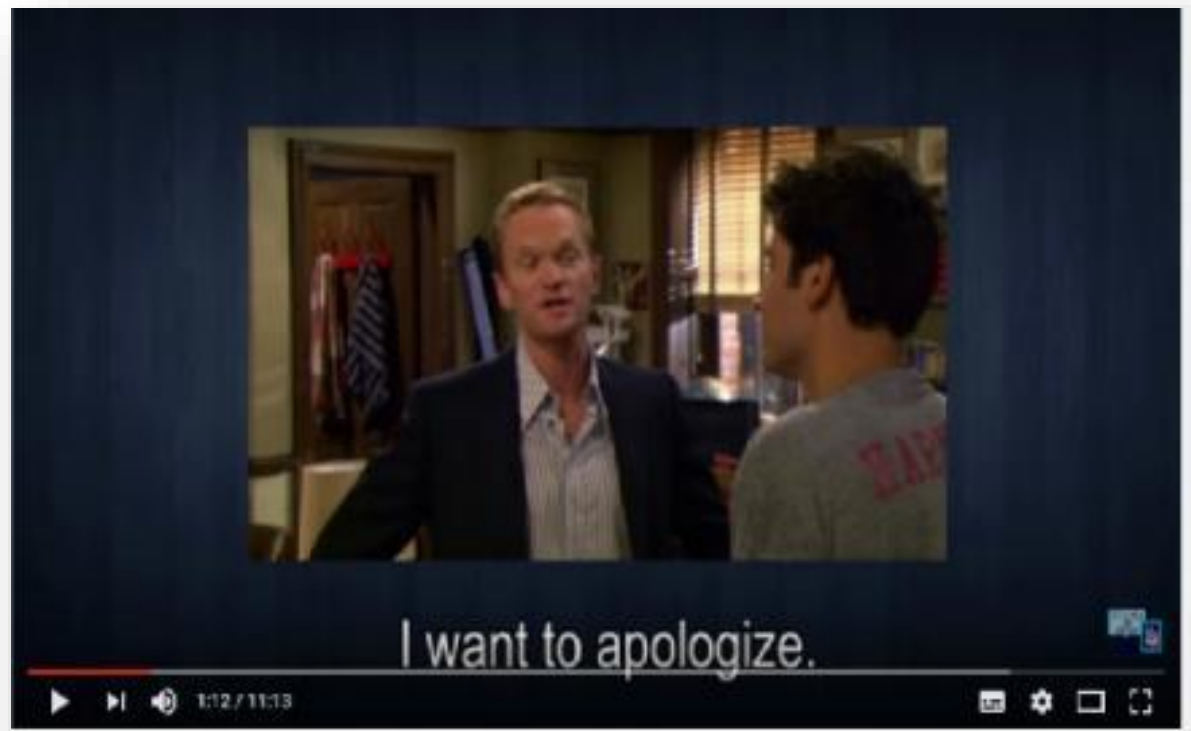

Anrendia innlếs com séries. HOW IMFT YOI R MOTHFR \#2 ISn3Fn1] 
Fig. 5 - canal Inglês com Série - Disponível em: <https://www.youtube.com/watch?v=XJJRbB4P01Q>

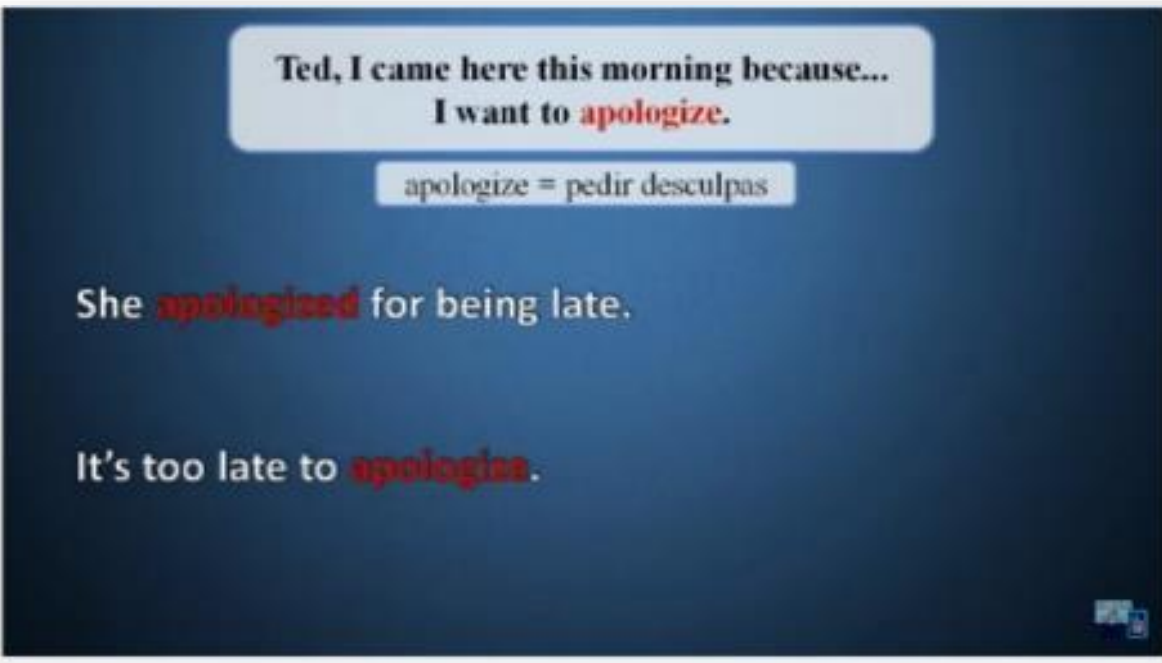

Aprenda inglès com séries - HOW I MET YOUR MOTHER *2 [SO3E01]

No sexto exemplo o apresentador, ainda ausente, faz um trabalho mais detalhado, focando na pronúncia das palavras ditas. Elas são apresentadas nas cenas considerando a forma em que elas são pronunciadas levando em conta os sons das letras com suas transcrições fonéticas, mostrando ao interlocutor sua forma correta de pronunciar.

Fig. 6 - canal Inglês com Série - Disponível em: https://www.youtube.com/watch?v=XJJRbB4P01Q

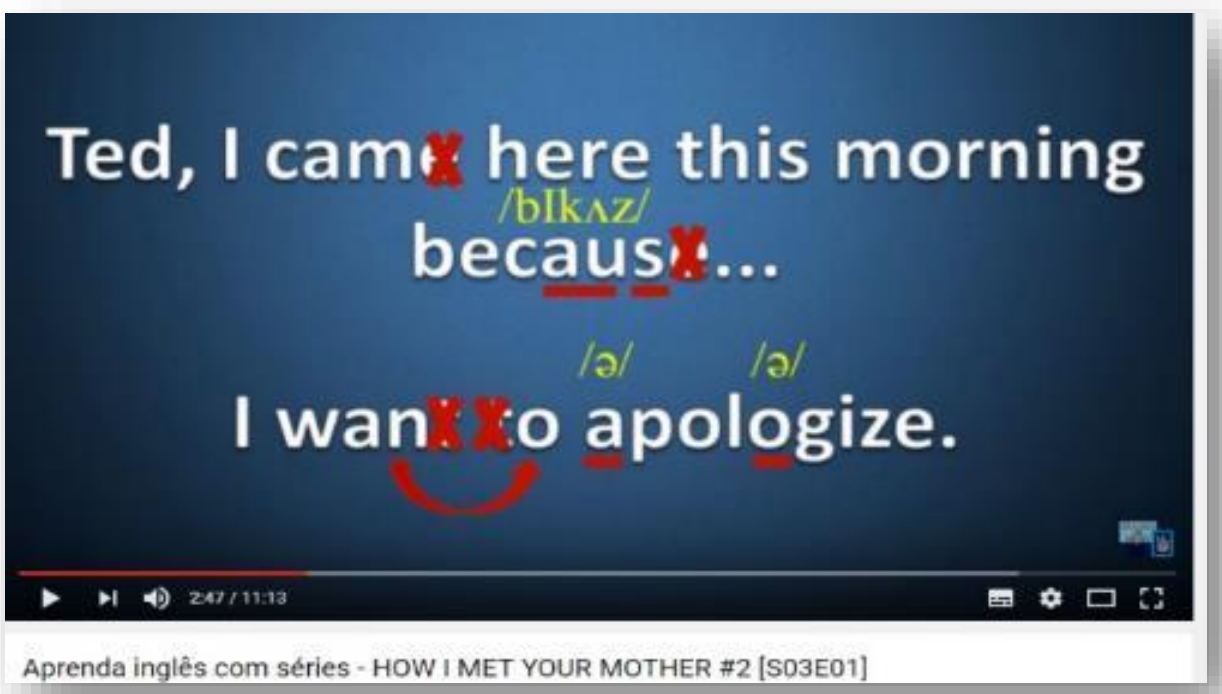

Uma das possíveis vantagens do canal é o uso de cenas de séries, uma ferramenta que ao mesmo tempo é descontraída e de fácil aprendizagem por se tratar de um recurso que as pessoas gostam e se interessam. Sendo assim, um meio prático que prende a atenção e estimula a curiosidade do aluno que se encontra motivado a aprender a língua por esse método. Uma das possíveis desvantagens do canal é que ele traz o foco somente na pronúncia e no vocabulário de algumas palavras não se aprofundando assim em outros aspectos necessários para aprender uma língua. 


\section{Sobre o segundo - Jennifer ESL}

Características: Jennifer ESL ou English with Jennifer é um canal de ensino de inglês, apresenta vocabulário, gramática e aulas especialmente voltadas para a pronúncia que abrangem diversos temas do dia a dia e curiosidades. As aulas são todas administradas em inglês e com vários recursos visuais. Os vídeos duram geralmente em torno de 1 a 14 minutos.

Recursos audiovisuais: o canal é apresentado por uma mulher, contém áudio em inglês, quadro para as anotações, objetos que ajudam a decifrar o significado dos vocábulos, desenhos e vários utensílios que auxiliam na compreensão das palavras, além de mudanças de cenários e participações de outras pessoas que tornam as aulas mais dinâmicas. Seguem os prints como exemplo do material que está disponível nos vídeos do canal analisado.

Fig. 7 - canal Jennifer ESL - Disponível em: https://www.youtube.com/watch?v=StCZIxz-mJU>

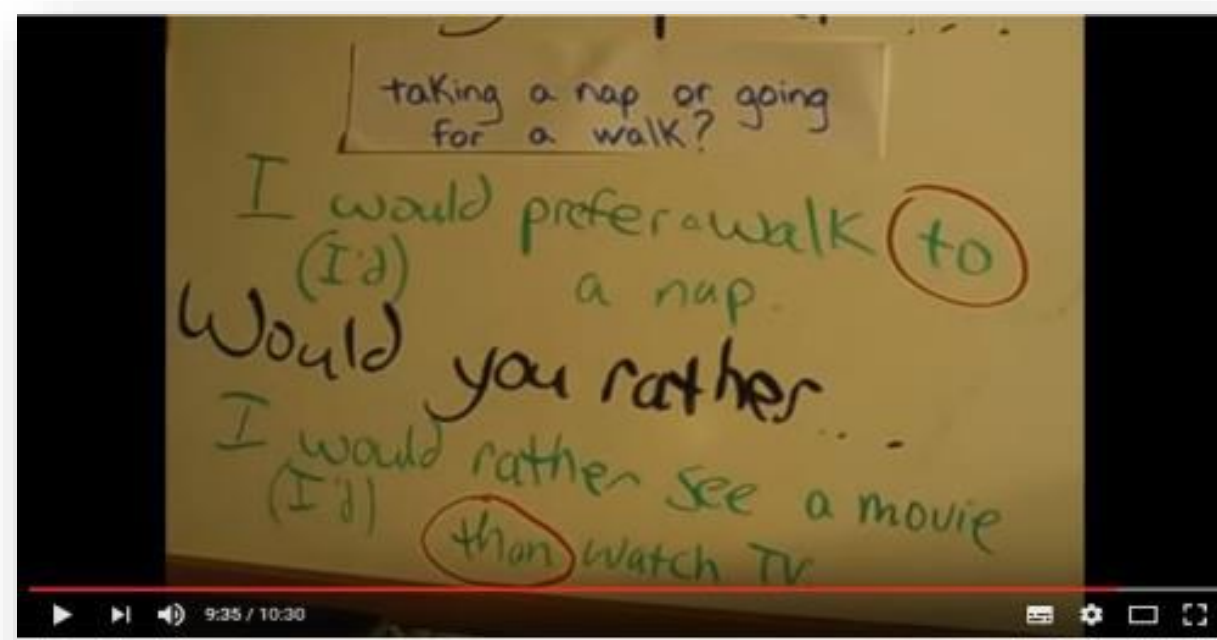

Lesson 1 - Preferences - Enalish Grammar

O canal ensina a pronúncia de frases aleatórias visualizadas no quadro branco onde a apresentadora, ausente fisicamente, segue lendo e fazendo a entonação das palavras para compreensão do interlocutor. Por ser um canal de nível mais avançado não existe a tradução da palavra, pois se espera que o interlocutor já esteja familiarizado com os termos que estão sendo apresentados.

No segundo exemplo abaixo, a apresentadora (ausente) foca na pronúncia de palavras que tem sons parecidos ajudando na compreensão delas. 
Fig. 8 - canal Jennifer ESL - Disponível <https://www.youtube.com/watch?v=cbpE6fW4jgo\&index= 2\&list $=$ PL81BCA0A2CB139CB7>

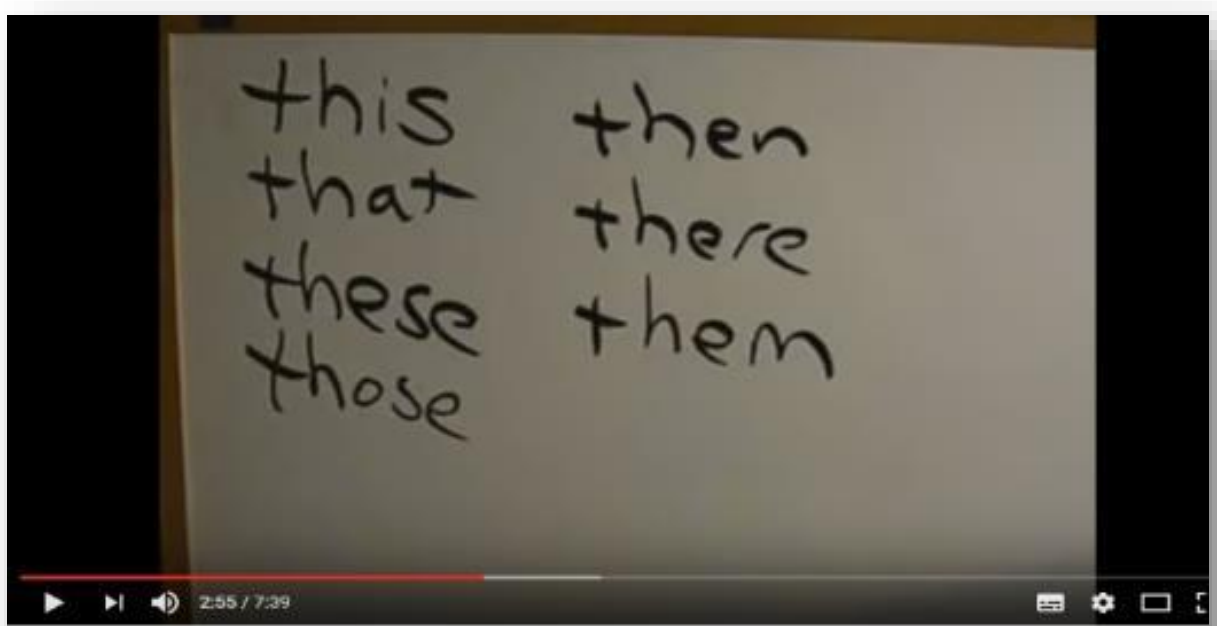

No terceiro exemplo a apresentadora (também ausente) traz o uso de exemplos de algumas expressões comuns utilizadas por nativos da língua inglesa, focando na pronúncia e em alguns momentos mostrando onde e de que forma as expressões podem ser utilizadas.

Fig. 9 - canal Jennifer ESL - Disponível em: <https://www.youtube.com/watch?v=TO8yfWMU2Yc\&index= 2\&list $=$ PLF66381FB978489F0>

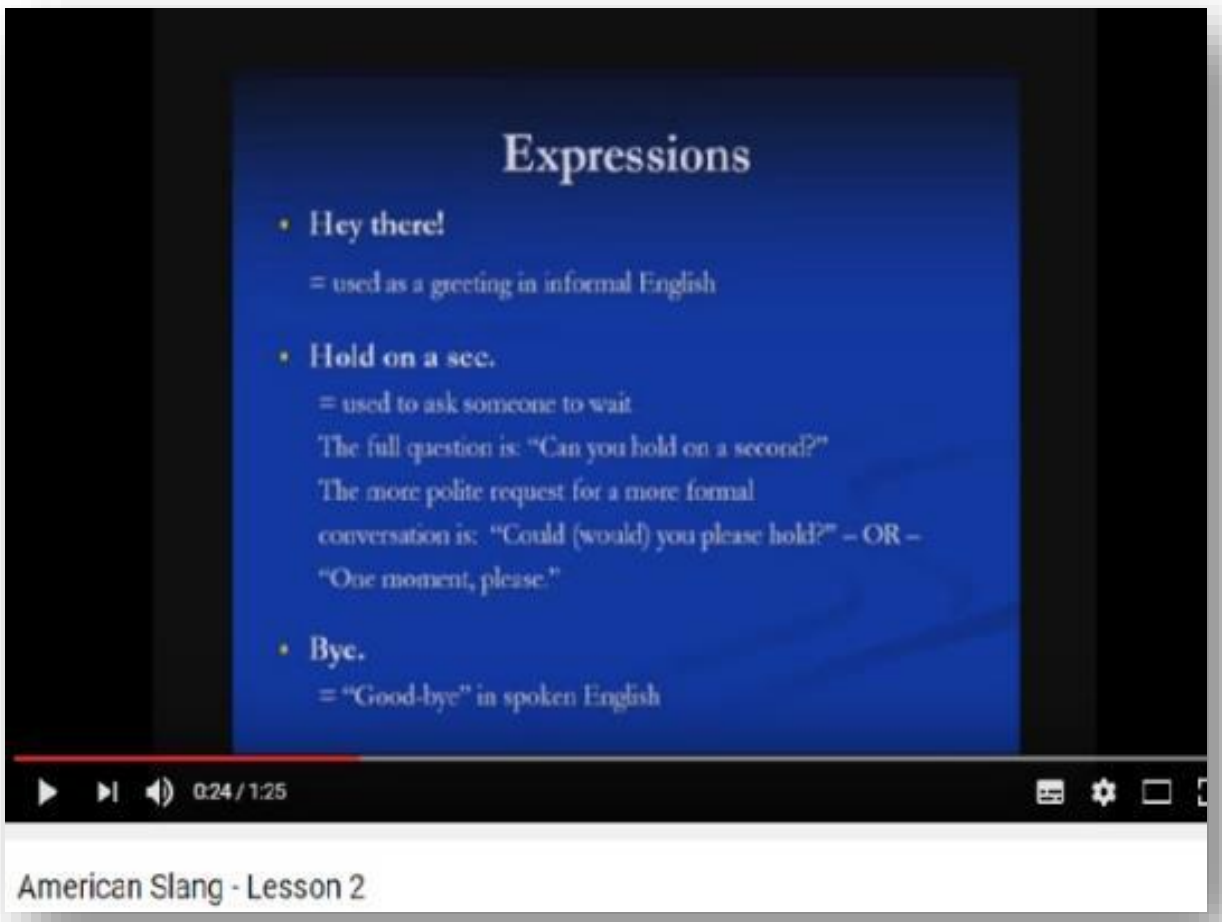

No quarto exemplo a apresentadora usa o do contato visual como um reforço do seu método que é o uso de um cenário como referencial daquilo que ela está dizendo, como é o exemplo 
da imagem abaixo. Ela está falando do tempo (com a legenda explicita) o qual condiz com o lugar em que ela se encontra.

Fig. 10 - canal Jennifer ESL - Disponível em: < https://www.youtube.com/watch?v=bpYCo23tTpo>

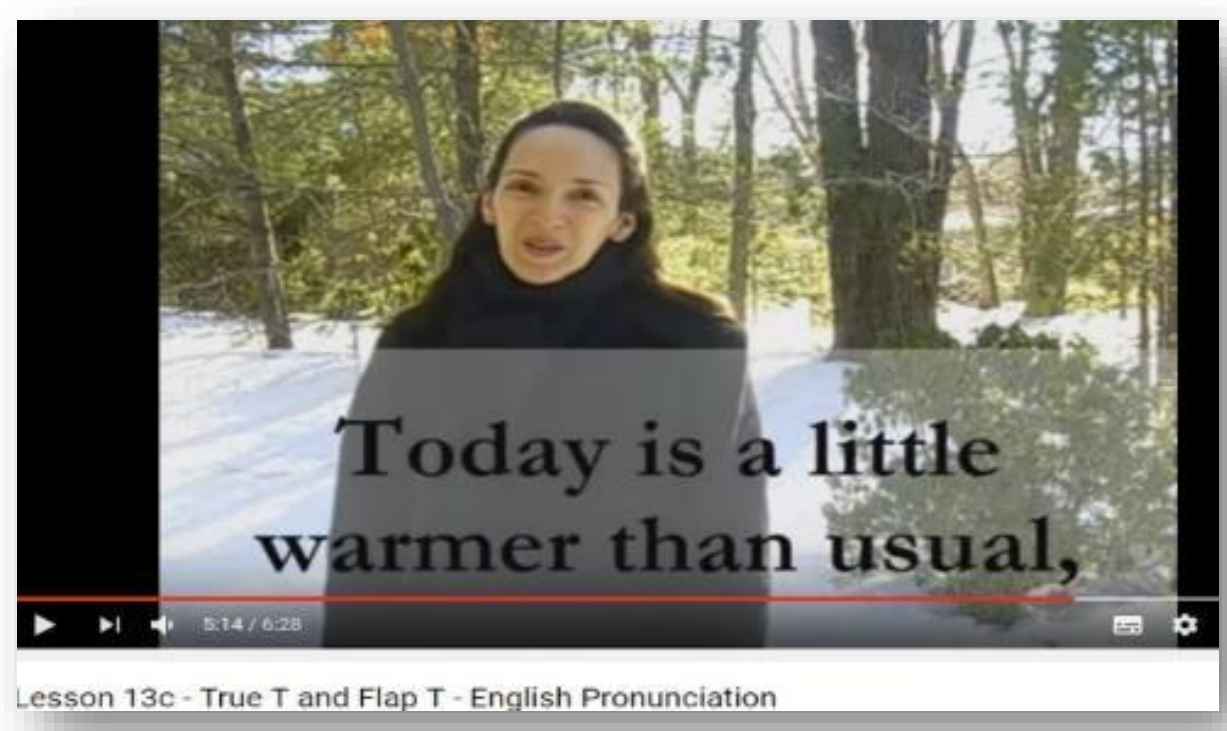

Uma das possíveis vantagens desse canal é que ele traz um material bastante extenso em se tratando do ensino da LI, além de fatos e curiosidades sobre ele. Aborda temas diversificados o que mantém o aluno informado em vários quesitos em relação á língua e também usa de estratégias que ajudam o aluno na fixação do conteúdo além de mantê-lo interessado naquilo que está sendo ensinado. Uma das possíveis desvantagens do canal é que ele somente usa da fala e da escrita em inglês fazendo assim que o canal não seja útil para os iniciantes do ensino-aprendizado da língua.

\section{Sobre o último - Inglês Winner}

Características: Inglês Winner é um canal de ensino de inglês para aqueles aprendizes que estão no "início da jornada". Com aulas didáticas e com foco no inglês para conversação, as aulas abrangem diversos assuntos sobre diferentes situações (expressões, gírias, frases e palavras para se usar em restaurantes, aeroportos etc.). Contém recursos audiovisuais variados que prendem a atenção do aprendiz e que ajudam na fixação do conteúdo. Os vídeos duram geralmente em torno de 1 a 10 minutos.

Recursos audiovisuais: o canal é apresentado por um homem que ministra as aulas em português e que faz uso de músicas, cenas de séries, legendas, imagens e variação de cenário como recursos didáticos. Seguem os prints como exemplo do material que está disponível nos vídeos do canal analisado. 
Fig. 11 - canal Inglês Winner - Disponível em: https://www.youtube.com/watch?v=XbL9_FDaVYU\&list $=$ PL7BDB07039775D0A6\&index $=>$

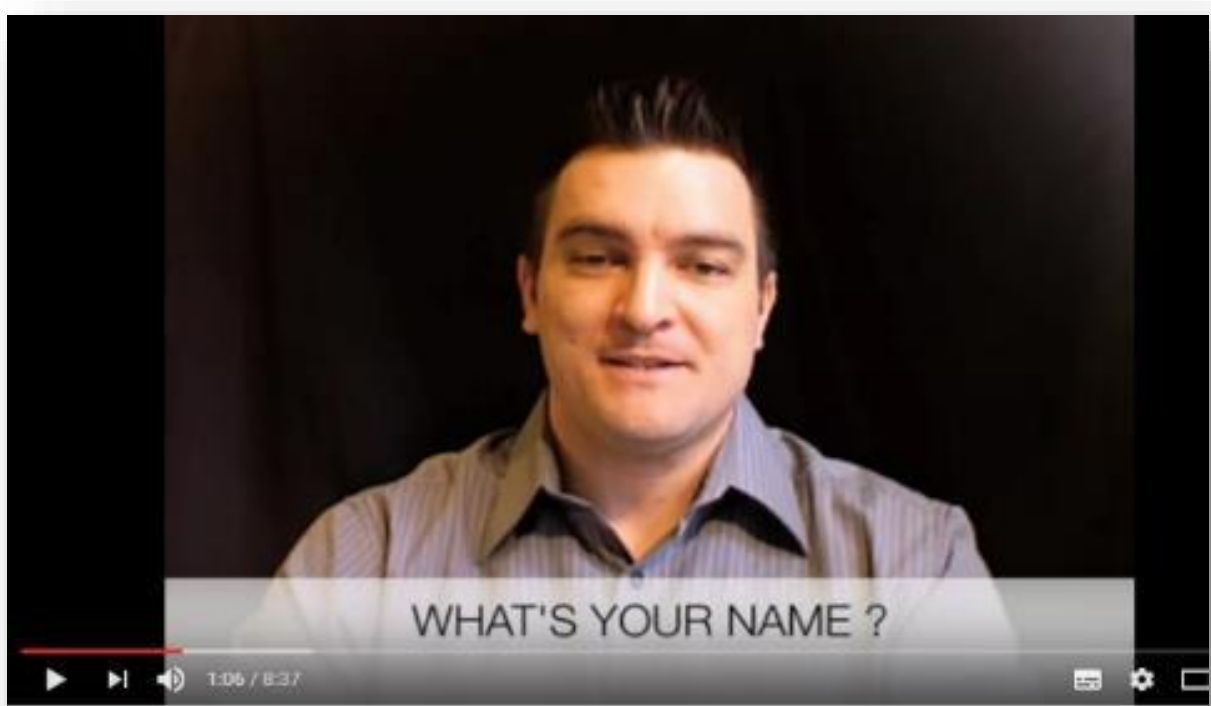

Aula de inales Basico \#1 - Informacōes Pessoais

O canal utiliza da troca visual entre o apresentador e o interlocutor como o método de ensino, além da legenda em inglês visível como ferramenta para ajudar na compreensão daquilo que está sendo dito, o apresentador parece estar tentando fazer uma conexão com o interlocutor para a aprendizagem do conteúdo.

No segundo exemplo abaixo, o apresentador ainda usando o método da troca visual entre professor e aluno, utiliza um telão onde ele faz a apresentação de exemplos de frases com o verbo to be, foco de ensino dele para aquela aula.

Fig 12 - Inglês Winner - Disponível em: <https://www.youtube.com/watch?v=Vn2gEy2jVyI\&index=11\&list= PL7BDB07039775D0A6>

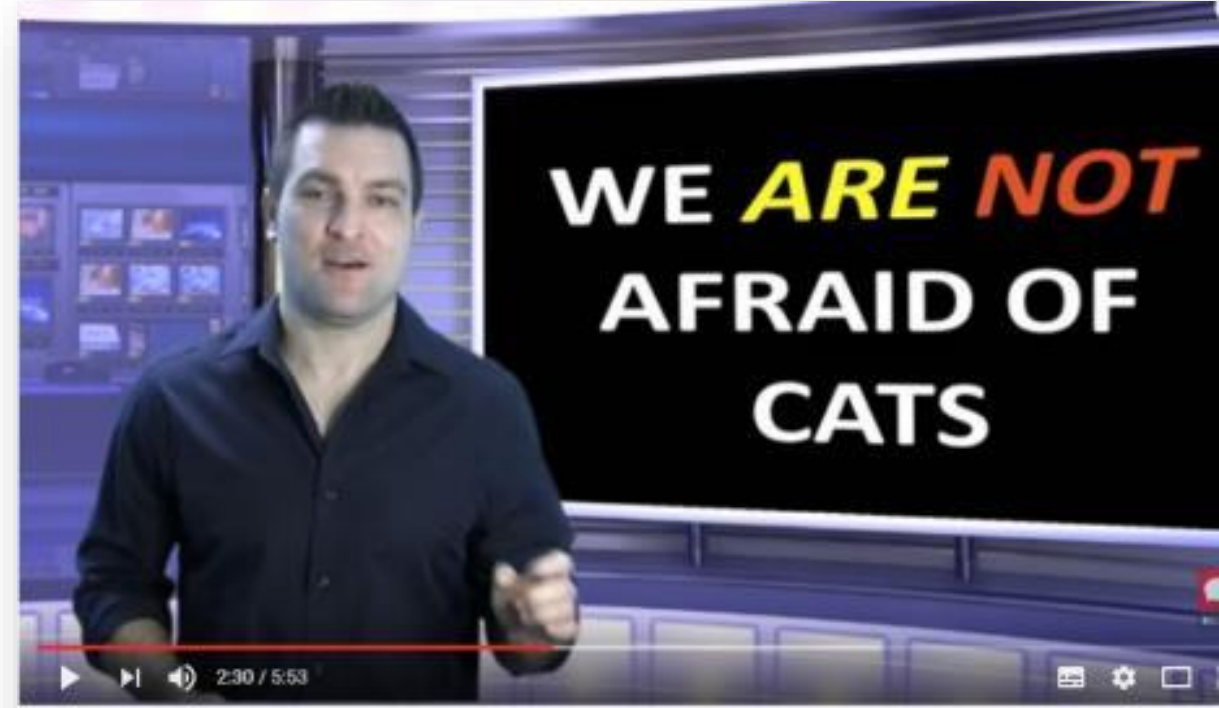

O apresentador utiliza da música para buscar uma interação com os aprendizes. Ele faz uso 
da letra de uma música, coloca a legenda na tela e logo após, faz a tradução das palavras oralmente, o que possibilita que aluno possa aprender tanto a pronúncia quanto o ajuda a enriquecer seu vocabulário.

Fig. 13 - canal Inglês Winner - Disponível em: < https://www.youtube.com/watch?v=xuayU8CLW0E >

(ISSN 2238-8060)

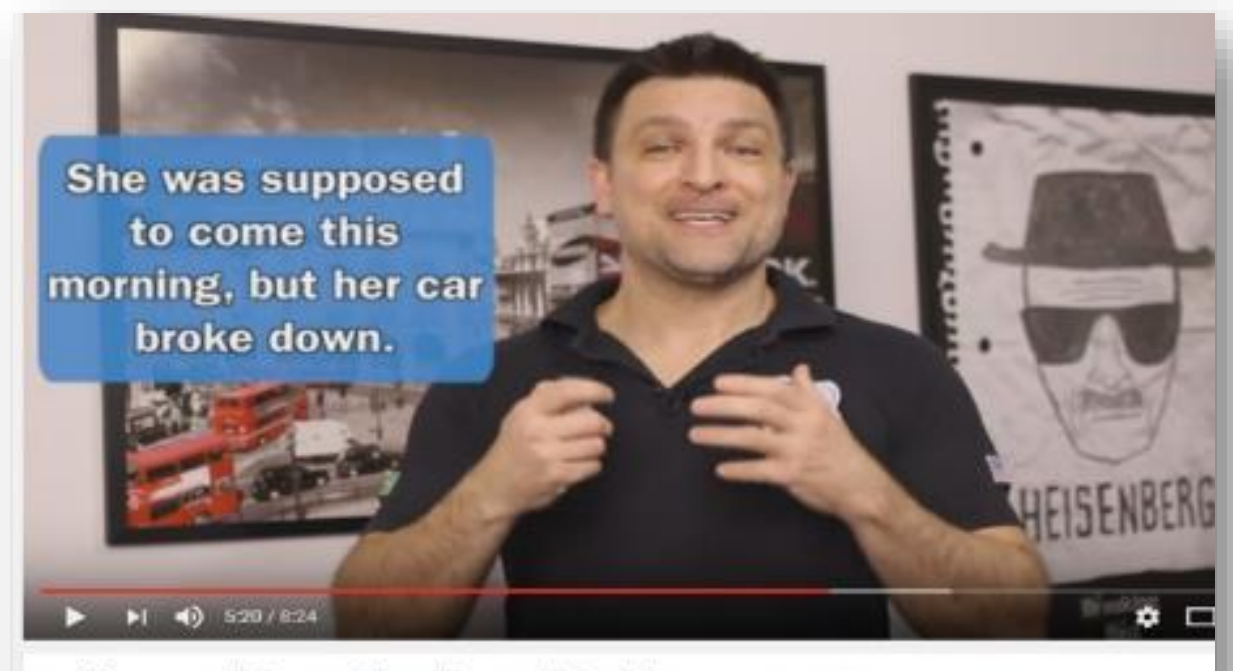

Inglês Com Música | Adele Hello - English with Songs Part - \#1

Uma das possíveis vantagens desse canal é que ele utiliza dos recursos audiovisuais de formas descontraídas auxiliando aqueles que estão começando a aprender inglês. Seus métodos ajudam a "prender" a atenção do aluno e também a instigar sua curiosidade para além do que está sendo apresentado, fatores estes importantes quando se trata de ensinar e aprender uma língua. Uma das possíveis desvantagens desse canal são vídeos de conteúdo da matéria de curta duração, o que pode dificultar na fixação do que está sendo ensinado por parte dos alunos que encontram dificuldade no aprendizado de outra língua.

Com o intuito de fazer uma relação direta dos canais de Youtube e sistematizar tudo que foi apresentado, temos os quadros comparativos entre eles focando nos termos específicos do que cada canal disponibiliza. Em se tratando de conteúdo de aprendizagem, esta sistematização viabiliza analisar de forma rápida o que cada um deles pode oferecer e para que tipo de público ele pode ser útil.

Quadro 1 Níveis

\begin{tabular}{|lll|}
\hline \multicolumn{1}{|c|}{ Básico } & \multicolumn{1}{c|}{ Intermediário } & \multicolumn{1}{c|}{ Avançado } \\
\hline Inglês com Séries & Inglês com Séries & Jennifer ESL \\
Inglês Winner & Inglês Winner & \\
\hline
\end{tabular}

Quadro 2 Recursos audiovisuais: séries e musicas

\begin{tabular}{|l|l|}
\hline Séries & Músicas \\
\hline Inglês com Séries & Inglês Winner \\
Inglês Winner & \\
\hline
\end{tabular}

Quadro 3 Conteúdo: Gramática, vocabulário/expressões e gírias, pronúncia

\begin{tabular}{|lll|}
\hline Gramática & Vocabulário/Expressões e Gírias & Pronúncia \\
\hline Jennifer ESL & Inglês com Série & Inglês com Séries \\
& Jennifer ESL & Jennifer ESL \\
& Inglês Winner & \\
\hline
\end{tabular}


Nesses quadros comparativos podemos perceber que a evolução das tecnologias digitais viabilizou as diversidades no site do Youtube. Em outras palavras, os recursos multimodais encontrados nele, podem vir a tornar o processo de ensino-aprendizagem de línguas muito diversificado e motivador. Com a análise comparativa apresentada neste artigo é possível auxiliar tanto professores quanto alunos a explorar esse recurso de forma crítica, deixando de perceber esses canais apenas como diversão e distração, para um meio produtivo e acadêmico de se construir conhecimento.

\section{Considerações finais}

As perspectivas e desafios do ensino de LI em um mundo globalizando onde inovações nos métodos de ensino acontecem a cada artefato digital inserido no mercado, não param de motivar os sujeitos envolvidos com ensino-aprendizagem de línguas a pesquisar. Visando acompanhar as transformações e a novas descobertas que vão sendo feitas, nos diversos setores da sociedade em relação ao uso do computador conectado a internet, os contextos educacionais - escolas, faculdades e universidades se desdobram para compreender e adaptar seus currículos à influência deste artefato no cotidiano das pessoas. É por essa razão que o trabalho defende a ideia de se conhecer a TD e a inserir em sala de aula como ferramenta mediadora de ensino. O objetivo de mostrar que o site Youtube, pode vir a ser útil, interessante, e inovador para se ensinar e aprender a LI, nada mais é do que oferecer oportunidade para o professor utilizá-lo de uma forma didática em seu contexto de atuação.

\section{Referências}

DUARTE, V. C.; TITO, M. R. A. Atitudes facilitadoras do professor: utopia ou possibilidade. In: CELANI, Maria Antonieta Alba (Org.). Reflexões e ações (trans)formadoras no ensino-aprendizagem de inglês. Campinas: Mercado de Letras, 2010. Cap. 1.p.15-36.

GODOY, A. S. Introdução à pesquisa qualitativa e suas possibilidades. Revista de Administração de Empresas. São Paulo, v. 35, n. 2, p.57-63, abr. 1995.

GRIGOLETTO, M. O inglês na atualidade: uma língua global. Enciclopédia das línguas do Brasil. Disponível em: http://www.labeurb.unicamp.br. Acesso em: 09/08/2016.

INSTITUTO DE PESQUISAS PLANO CDE. O Ensino de Inglês na Educação Pública Brasileira: Elaborado com exclusividade para o British Council pelo Instituto de Pesquisas Plano CDE. São Paulo: British Council, 2015. Disponível em: https://www.britishcouncil.org.br. Acesso em: 07 ago. 2016.

KAMPFF, A. J. C.; DIAS, M. G. C.. Reflexões sobre a construção do conhecimento em ambientes de pesquisa e de autoria multimídia: uma tarefa compartilhada por alunos e professores. RENOTE, v. 1, n. 2, 2003.

LEFFA, V. J. A aprendizagem de línguas mediada por computador. Pesquisa em linguística aplicada: temas e métodos. Pelotas: Educat, p. 11-36, 2006.

LIBERALI, F. C. Atividade social como base para o ensino de língua estrangeira. In: CANO, Márcio Rogério de Oliveira (Org.). A reflexão e a prática no ensino. 2. ed. São Paulo: Edgard Blücher Ltda, 2012, p. 21-34.

MARCUSCHI, L.A. Apresentação: interação na Internet. In: ARAÚJO, Júlio César; BIASIRODRIGUES, Bernadete (Org.). Interação na Internet: novas formas de usar a linguagem. Rio de Janeiro: Lucerna, 2005.

MORAN, J. M. O Vídeo na Sala de Aula. 1995. Disponível em: http://penta2.ufrgs.br/figuras/ vidsal.htm. Acesso em: 16/10/2016.

PAIVA, V. L. M. O. de. O uso da tecnologia no ensino de linguas estrangeiras: breve retrospectiva histórica. 2008. Disponível em: http://www.veramenezes.com. Acesso em: 09/08/2016 
PAVAN, C. A. G.; OGER, L. A. Globalização, cultura e ensino de línguas. 2009. Disponível em: http://docplayer.com.br/2719770. Acesso em: 09/08/2016.

STOCKWELL, G. Computer-Assisted Language Learning: diversity in research and practice. Cambridge, 231 p. 2012.

VIEIRA, P. Tecnologias na educação: ensinando e aprendendo com as tic e elaboração de projetos. 2010. Disponível em: http://patotatics.blogspot.com.br. Acesso em: 14/11/

2016.

WERNECK, C. L. L.; CRUZ, E. P. O uso do youtube como ferramenta de marketing: estudo de caso da imobiliária tecnisa. Pensamento Contemporâneo em Administração, Rio de Janeiro, v. 3, n. 3, p. 1-20, set. 2009.

Recebido em: 07/12/2018

Aceito em: 03/07/2019 